\title{
A Study of Strengths and Weaknesses of Descriptive Assessment from Principals, Teachers and Experts Points of View in Chaharmahal and Bakhteyari Primary Schools
}

\author{
Mostafa Sharief ${ }^{1}$, Mahin Naderi ${ }^{1}$, Maryam Shoja Hiedari ${ }^{1}$, Omolbanin Roodbari ${ }^{1}$ \& Mohammad Reza Jalilvand ${ }^{1}$ \\ ${ }^{1}$ Department of Educational Sciences, Faculty of Educational Science \& Psychology, University of Isfahan, Iran \\ Correspondence: Mohammad Reza Jalilvand, Department of New Sciences and Technologies, University of \\ Tehran, Tehran, Iran. Tel: 98-913-828-4778. E-mail: rezajalilvand@ut.ac.ir
}

Received: March 17, 2012 Accepted: March 27, 2012 Online Published: June 15, 2012

doi:10.5539/ies.v5n4p11

URL: http://dx.doi.org/10.5539/ies.v5n4p11

\begin{abstract}
The aim of current study is to determine the strengths and weaknesses of descriptive evaluation from the viewpoint of principals, teachers and experts of Chaharmahal and Bakhtiari province. A descriptive survey was performed. Statistical population includes 208 principals, 303 teachers, and 100 executive experts of descriptive evaluation scheme in Chaharmahal and Bakhtiari province from 2011 to 2012. Sample size was estimated 175 respondents and a random-category sampling plan was employed to collect the estimated sample that contains 100 teachers, 50 principals and 25 experts. To identify the validity of instrument, opinions of twelve persons including advisor professor, consulting professor, designer of the descriptive evaluation scheme, four of educational planning department professors and five of experts holding Master and Ph.D. degrees that are executives of the scheme in Chaharmahal and Bakhtiari were utilized. To determine the consistency of the instrument, Chronbach's alpha was used $(\alpha=0.90)$. We used SPSS software to analyze data. To answer the research questions, paired sample t-test, ANOVA analysis, and least significant difference (LSD) test were used. Results revealed that the executives of descriptive evaluation scheme in Chaharmahal and Bakhtiari province evaluate the so-called scheme above average regarding to four scales (strength and weakness).
\end{abstract}

Keywords: descriptive evaluation, strength, weakness, school

\section{Introduction}

During the past few years, there have been extensive arguments over educational reforms in schools. The evaluation of students is considered as a key factor in school reformation and improvement in education and learning (Seif, 2010). Dissatisfied with traditional forms of evaluation, most countries decided to revise and reconsider their evaluation systems. During the last two decades, the researchers in this field have also proposed new methods of evaluation. This new method is called descriptive evaluation as opposed to the traditional system of evaluation and based on new educational attitudes to combat the challenge the educational system faces (Hassani \& Ahmadi, 2005). The system of descriptive evaluation was passed in the $296^{\text {th }}$ summit of the supreme council of education along with setting goals for the tentative scheme of descriptive evaluation in elementary school students with one of its main objectives being the reformation of education - learning process in classrooms. An increased mental stability (stability of learning), increased interest in learning, attention to the objectives of non-cognitive areas are considered as other objectives of this project (Hassani, 2006). It is expected that the proper evaluation will pave the way for educational reforms. In traditional educational systems, evaluation was performed as the last step in order to make judgments about the students going on to higher levels. Currently, evaluation is an indispensible part of the teaching - learning process, which focuses on leading the students' learning rather than classifying them (Pasha Sharifi, 2004). Hence, the main objective of the present study is to evaluate the strengths and weaknesses of the descriptive evaluation from the point of view of teachers, principals and experts in Chaharmahal and Bakhtiari. In the next sections, a review of literature, the importance of the study and the questions of the study are presented. Finally, the methodology and results will be discussed.

\section{Literature Review}

The results of a study conducted by Hebdige (2003) on evaluating Croatian students without giving grades showed that the students and teacher were satisfied with this kind of evaluation with less anxiety and more 
psychological health. Teachers who were more skillful in conducting this kind of evaluation had fewer problems with their students, who learned better.

Ghazi Ghaith (2003) noted that when an interactive and cooperative method of teaching and evaluating is adopted in a classroom, the students hold a more positive view towards a fair system of grading by the teacher, solidarity and integrity and a supportive atmosphere in class. However, competitive and individualistic methods resulted in reverse outcomes.

Van Evera (2004) studied the effectiveness of evolutionary feedbacks in the performance and motivation of the students in science classes of juniors in high schools. In this study, the students received written feedback for their homework and class assignments, while the control group received grades, without any other feedbacks. The findings indicated that the feedback of evaluation led to a significant increase in the students' efficiency in junior high school.

Waddel (2004) studied the influences of written feedbacks in evolutionary on the students' motivation and objective orientation. In this study, 79 fourth grader elementary school children were studied. The first study was a return scheme of $\mathrm{ABAB}$, which was performed in order to support the cause-and-effect relationship between feedback grades (i.e. evaluation based on the Rubric of written feedback of the teacher) and the effectiveness of the feedback (i.e. the students' attitudes towards the value of the written feedback). The results of the covariance analysis revealed that the examination group reported a significantly higher level of objective orientation. The overall linear model, using frequent measurements, supported the relationships among the feedback grades and also between the homework grades and the feedback grades. However, the relationship between the effectiveness of the feedback and educational performance was not significant.

Arthur (2004) studied the influence of performance feedback, prior improvement, homework complexity, and cultural knowledge on the personal mathematical efficiency as well as on personal evaluation of African-American students. The sample consisted of 72 fourth and fifth- grader elementary school students. In this study, prior knowledge was introduced into the analysis as the auxiliary random variant and two three-way MANCOVA tests were performed. The results of both analyses showed a significant main influence on the personal evaluation based on the performance feedback. Furthermore, in the second analysis, prior knowledge led to a significant main effect on the personal efficiency.

Gest et al. (2005) and Sammons and Reynolds (1977) noted that the most proper form of evaluation of the effectiveness of the school and making sure of the quality of the school is to study the effects of academic behaviors and the evaluation of knowledge and other actions performed by the school and class on the social and emotional feedbacks of the students.

Saeed et al. (2005) studied the improvement level of elementary students in Pakistan. The sample consisted of 1080 third and fifth grader elementary students randomly selected from 36 elementary schools in the nine zones of the Punjab province. The tools used in this study included improvement tests in three academic subjects of math, Urdu (the official language) and life skills (Islamism, social studies, and sciences). Some part of the results showed that the improvement level of the third graders in Urdu was low, being 15.2 and life skills was high, being 29.9. However, the fifth graders showed their highest level of improvement in life skills with 31.63 and their lowest level of improvement in math with 10.8. Overall, the improvement of the girls was better that that of boys. In addition, the students in the rural areas outperformed the students in urban areas.

Lubbers (2006) indicated that if the evaluation system adopted in the classroom creates positive emotional atmosphere with strong social relationships, the students would show a higher academic improvement. Various studies indicate that the psychological well-being of the students is related to their academic improvement, and students who suffer from some kind of psychological problems or lack of psychological health often face educational failure (Bradby et al., 2007). Loukas and murphy (2007) conducted a study on 488 students between the ages from 10 to 14 to study four aspects of the class atmosphere, namely conflict, solidarity, and competition among students and their satisfaction with the class. They suggested that a peaceful, supportive, less competitive, and more satisfactory atmosphere, with high solidarity among students play a key role in their psychological well-being.

\section{The Importance of Study and the Research Questions}

The academic evaluation system is one of the components of the educational system, which connects education and learning. It is one of the factors improving these two components. The evaluation of academic improvement is an important subject that has received a significant attention from educational experts and policy-makers (Nevo, 1995). Educational evaluation involves the process of planning, development and provision of descriptive 
information about the components of the curriculum (MehrMohammadi, 2002). Evaluation motivates students to learn how to learn. Teachers should judge the students' weaknesses and strengths based on studying the results of the evaluation and considering academic goals and expectations and propose some tips for the improvement of the students' learning activities and psychological well-being (ZeiniVand, 2008). One of the most important issues overlooked in some societies and therefore in planning and developing infrastructures, is the differences among students. Obviously, one of the most challenging issues the educational system has always faced is whether the role of the educational system is to educate the elite or to educate all children and students regardless of their differences (Armion, 2008). The UNESCO notes the urgency of developing modern solutions to the problems human beings face in the $21^{\text {st }}$ century, as if feeling there should be different methods in educational systems than the old and traditional ones (Tawil, 2002). The descriptive evaluation was proposed as opposed to traditional method of evaluation and it is based on new strategies for facing the government's challenges. The descriptive evaluation is the process of gathering, analyzing and interpreting information using different tools (paper-pencil tests, performance tests, recording observations, checking homework assignments, tasks and so on) about different aspects of the learning and decision making process and providing useful descriptive feedbacks in order to direct this process to a better understanding of goals (Hassani, 2009). When the educational evaluation stops traditional or quantitative way, there is no longer a marked difference between students with special needs and their normal peers, because the criteria for evaluation is not just getting grades in exams, and students at any age (perhaps both genders) are provided with unlimited opportunities to test their talents in different areas and get social and personal achievements. These opportunities could be athletic, academic, scientific, artistic, technical, etc. (Foster, 2007). The advantages of the descriptive evaluation include expressing weaknesses and strengths in learning, providing suitable solutions to problems, and respecting individual differences between students. In this form of evaluation, each student is tested against himself/herself and is not compared to other students with different skills and abilities (Habibi, 2008). Research shows that evaluating improvement is a complicated and vague challenge (Kanter et al., 1992). One challenge that the educational evaluation system faces is lack of a proper propagation pattern for developments in this area. In fact, the problem of spreading innovation and general changes is an important challenge of the overall educational system of the country and the subsystem of evaluation will inevitably suffer. One serious challenge for a sound a logical set up of this plan is the negative attitude parents and societies have toward this plan. An early study conducted by the bureau of evaluation shows obvious negative attitudes. Therefore, a comprehensive plan needs to be developed to correct the attitude of the teachers (MoghniZade, 2004). Educational experts consider evaluation as a key factor in improving schools, teaching methods of teachers and learning of students (Stigins, 2004). The concept of competency is among the concepts that have been extensively discussed. It could be defined as the ability to use knowledge, attitudes and skills in an inventive and effective way, in different situations (Farstad, 2004). Since the process of teaching and learning is not completed without evaluation, a proper evaluation could be considered as the art of the teacher. Therefore, it is vital that the teachers gain necessary skills for proper evaluation in order to trigger learning, judging and critical thinking in learners (Habibi, 2008). In the descriptive evaluation scheme in schools, the learning is improved through an emphasis on qualitative evaluation, performance evaluation, and giving descriptive feedback (Seif, 2003). The complementary stage of the evaluation requires that both teachers and students' roles change (Teresa, 2004). International research shows that there have been great advances in changing school curriculums in many countries. Some Asian countries such as Bangladesh, Sri Lanka, India, and the Philippines have started the competency-based plan to meet the needs of the modern society (UNESCO, 2000). Eastern European countries have adopted lot of changes, one of them being competency-based plan (West Creighton, 1999). Although the evaluation is a part of the teaching and learning process, it plays a much bigger role and its effects on the subsystems of educational systems are more significant. Therefore, it is required that, prior to the spread of the new evaluation method in the country, its weaknesses and strengths are studied through scientific researches to help enforce it in the best way. It is expected that the results of the study have useful implications for professionals in teaching, teachers and parents to work for improving the descriptive evaluation and paving the way for performing it in the best way. Based on prior discussion, the research questions are as follows:

1) Do teachers, principals, and experts performing the scheme in Chaharmahal and Bakhtiari consider its strengths as higher than average?

2) Do teachers, principals, and experts performing the scheme in Chaharmahal and Bakhtiari consider its weaknesses as higher than average?

3) Do the opinions of principals, teachers and experts performing the scheme vary depending on demographic parameters such as age, gender, the number of working years (length of employment), position, and education? 


\section{Methodology}

This study is a descriptive-survey one. It is descriptive because the researchers try to describe the current situation regarding the strengths and weaknesses of performing descriptive evaluation from the point of view of principals, teachers and experts performing the plan and they use documents, questionnaires, and interviews. The data gathering instruments include interviews and questionnaires. Interviews were conducted to use the experiences of the performers of the scheme. Interviews were conducted individually and in person, in a semi-organized way, with questions predefined in line with the main components of the questionnaire. Since there was not a standardized questionnaire for current study, a self-administrated questionnaire was used. In doing so, the researcher first studied the literature and based on the results of the interviews and with the help of some experts tried to develop the questionnaire. During the pilot study, vague or overlapping questions were omitted and based on the opinions of the experts, a questionnaire with 74 close-ended questions and 4 open-ended questions was developed and its reliability was measured. The questionnaire consists of two parts that evaluate the strengths and weaknesses of performing the descriptive evaluation method, respectively. In order to determine the validity of questionnaire, professors, educational experts and 10 professionals with M.A and Ph.D degrees were asked for their opinions. To determine the reliability of the questionnaire, the Cronbach alpha was used. The reliability coefficient of "strength" was 0.98 and that of "weakness" was 0.80 and the total was 0.89 , indicating high reliability. The population consisted of all principals, teachers, and experts in the academic years 2011-1012, with 208 principals, 303 teachers, and 100 experts. The members of the sample were selected by random stratified sampling proper to the population. Due to inaccessibility of the population variance, a pilot study was randomly conducted for 30 performers of the plan and the variance of the sample was calculated. In the confidence interval of $95 \%$, the sample size was estimated 175. From 175 distributed questionnaires, all of them were retrieved and analyzed. Table 1 shows that, 100 teachers, 50 principals, and 40 experts made up the sample. The sample was distributed in a way that all parts of the province were taken into account. Therefore, the first and second zones of Shahre kurd, Kiar and Buldagi, were considered because the plan was performed completely during 2011-2012. Saman and Farsan also were considered because of high numbers of classes with the descriptive plan. To analyze data, descriptive analysis, paired sample t-test, one-way analysis of variance (ANOVA), and the least significance difference (LSD) test were used by SPSS software.

Table 1. Sample profile

\begin{tabular}{llll}
\hline Zone & $\begin{array}{l}\text { Sample of } \\
\text { teachers }\end{array}$ & $\begin{array}{l}\text { Sample of } \\
\text { principals }\end{array}$ & $\begin{array}{l}\text { Sample of } \\
\text { experts }\end{array}$ \\
\hline $\begin{array}{l}\text { Shahre kurd (First } \\
\text { Zone) }\end{array}$ & 40 & 10 & 6 \\
$\begin{array}{l}\text { Shahre kurd } \\
\text { (Second Zone) }\end{array}$ & 21 & 10 & 6 \\
Farsan & 15 & 6 & 4 \\
Saman & 14 & 6 & 3 \\
Kiar & 15 & 10 & 3 \\
Boldaji & 15 & 8 & 3 \\
Total & 100 & 50 & 25 \\
\hline
\end{tabular}

\section{Findings}

To answer the first two questions of the study, the single variable t-test (the mean of one population) was used. It is used for comparing variables in a population with specific standard. In this test, the hypothesis put forward regarding the mean population in the error level of $\alpha$ was studied. If the mean of each variable is higher than a certain degree (here 3) that variable in the component is considered effective. According to Table 2, for the scores of "strength", the observed $t$ in the error level 5\% is higher than the critical value, so the strengths of the descriptive evaluation is higher than average. In addition, for the scores of "weakness", the observed $t$ in the error level $5 \%$ is higher than the critical value, so the weaknesses of the descriptive evaluation are higher than average. 
Table 2. Comparing strength and weakness scores of descriptive assessment (mean=3)

\begin{tabular}{lllll}
\hline Factor & $\mathrm{X}$ & $\mathrm{s}$ & $\mathrm{se}$ & $\mathrm{t}$ \\
\hline Strengths & 4.41 & 0.443 & 0.033 & 42.20 \\
Weaknesses & 4.37 & 0.551 & 0.038 & 35.54 \\
\hline
\end{tabular}

Table 3. Comparing strength and weakness scores of descriptive assessment based on gender

\begin{tabular}{|c|c|c|c|c|c|c|}
\hline \multirow[t]{2}{*}{ Factor } & \multirow{2}{*}{$\begin{array}{l}\text { male } \\
X\end{array}$} & \multicolumn{3}{|c|}{ female } & \multirow[t]{2}{*}{$\mathrm{t}$} & \multirow[t]{2}{*}{$\mathrm{P}$} \\
\hline & & $S$ & $X$ & S & & \\
\hline Strengths & 4.43 & 0.414 & 4.39 & 0.476 & 0.647 & 0.501 \\
\hline Weaknesses & 4.41 & 0.480 & 4.32 & 0.542 & 1.07 & 0.285 \\
\hline
\end{tabular}

Table 4. Comparing strength and weakness scores of descriptive assessment based on position

\begin{tabular}{lllllllll}
\hline Factor & Expert & \multicolumn{5}{c}{ Teacher } & \multicolumn{3}{c}{ Principal } & F & P \\
& $\mathrm{X}$ & $\mathrm{S}$ & $\mathrm{X}$ & $\mathrm{S}$ & $\mathrm{X}$ & $\mathrm{S}$ & & \\
\hline Strengths & 4.44 & 0.454 & 4.12 & 0.557 & 4.47 & 0.384 & 5.24 & 0.002 \\
Weaknesse & 4.32 & 0.501 & 4.13 & 0.643 & 4.44 & 0.456 & 3.38 & 0.020 \\
$\mathrm{~s}$ & & & & & & & & \\
\hline
\end{tabular}

In order to investigate the significance of the differences between the respondents' opinions based on gender, position, education, and working years (length of employment), one-way ANOVA analysis was performed. According to Table 3 , the observed $t$ was not significant $(p>0.05)$. Therefore, there is not a significant difference between the weaknesses and strengths of the descriptive evaluation from the point of view of male and female respondents.

According to Table 4, observed $\mathrm{F}$ regarding strength and weakness of descriptive evaluation was significant ( $\mathrm{p}$ $\leq 0.05$ ). Therefore, there is a significance difference between the strengths and weaknesses of the descriptive evaluation regarding position. In other words, their responses to the two components are not the same based on their positions in elementary schools in Chaharmahal and Bakhtiari.

Table 5. Paired sample t-test for strengths of descriptive assessment based on position

\begin{tabular}{lll}
\hline Position & Mean difference & P-value \\
\hline Principal-teacher & 0.348 & 0.001 \\
Teacher-expert & 0.006 & 0.006 \\
\hline
\end{tabular}

Table 5 shows that the principals' responses are different from those of teachers. In other words, the experts' responses to the four components of principals with teacher and teachers with experts regarding performing descriptive evaluation in elementary schools of Chaharmahal and Bakhtiari are different $(\mathrm{P} \leq 0.05)$.

Table 6. Paired sample t-test for weaknesses of descriptive assessment based on position

\begin{tabular}{lll}
\hline Position & Mean difference & p-value \\
\hline Principal-teacher & 0.327 & 0.002 \\
\hline
\end{tabular}

Table 6 shows that there is a significant difference between the opinions of the teachers with those of the principals, regarding the component of weakness. In other words, the teachers' responses are different from those of principals to the component of weakness in Chaharmahal and Bakhtiari elementary schools $(p \leq 0.05)$. 
Table 7. Comparing strength and weakness scores of descriptive assessment based on education

\begin{tabular}{lcccccccccc}
\hline Factor & Ph.D & \multicolumn{6}{c}{ Post-graduate } & \multicolumn{2}{c}{ Bachelor's degree } & \multicolumn{2}{l}{ degree } & t & P \\
& $\mathrm{X}$ & $\mathrm{S}$ & $\mathrm{X}$ & $\mathrm{S}$ & $\mathrm{X}$ & $\mathrm{S}$ & $\mathrm{X}$ & $\mathrm{S}$ & & \\
\hline Strengths & 4.58 & 0.372 & 4.46 & 0.421 & 4.32 & 0.403 & 4.25 & 0.681 & 2.28 & 0.081 \\
Weaknesses & 4.64 & 0.258 & 4.39 & 0.500 & 4.30 & 0.508 & 4.26 & 0.682 & 1.57 & 0.197 \\
\hline
\end{tabular}

Table 7 shows that the observed $\mathrm{F}$ in $\mathrm{p} \leq 0.05$ was not significant. Therefore, there is not a difference between strengths and weaknesses of the plan in terms of education. In other words, the responses given by respondents with degree to $\mathrm{Ph}$. D to two components were the same.

Table 8. Comparing strength and weakness scores of descriptive assessment based on length of employment

\begin{tabular}{lllllllllll}
\hline Factor & $\begin{array}{l}\text { 21 years or } \\
\text { above }\end{array}$ & \multicolumn{1}{l}{$16-20$ years } & \multicolumn{1}{c}{$10-15$ years } & \multicolumn{2}{c}{$\begin{array}{l}\text { Less than } 10 \\
\text { years }\end{array}$} & $\mathrm{t}$ & $\mathrm{P}$ \\
& $X$ & $\mathbf{S}$ & $X$ & $\mathbf{S}$ & $X$ & $\mathbf{S}$ & $X$ & $\mathbf{s}$ & & \\
\hline Strengths & 4.36 & 0.405 & 4.48 & 0.390 & 4.40 & 0.303 & 4.29 & 0.602 & 1.76 & 0.157 \\
Weaknes & 4.28 & 0.574 & 4.43 & 0.461 & 4.33 & 0.413 & 4.30 & 0.604 & 0.939 & 0.423 \\
ses & & & & & & & & & & \\
\hline
\end{tabular}

Table 8 shows that the observed $\mathrm{F}$ in $\mathrm{p} \leq 0.05$ is not significant. There is not a significant difference between strengths and weaknesses based on the respondents' length of employment. In other words, the responses of the performers of the plan with less than 10 to more than 20 years of working to the two components of the descriptive evaluation in elementary schools of Caharmahal and Bakhtiari was the same.

Table 9. Maximum frequency of interviewed respondents to strength factor

\begin{tabular}{llll}
\hline Gender & Response to strength & Frequency & Percent \\
\hline Male & Increasing self-confidence among students & 14 & $47 \%$ \\
Female & Increasing knowledge and awareness among students & 15 & $50 \%$ \\
\hline
\end{tabular}

In Table 9, the highest frequency distribution in male responses to the component of strength is that performing the descriptive evaluation increases self-confidence in students, with 14 respondents i.e. $47 \%$ of the whole respondents.

The highest frequency distribution in female responses to the component of strength is that performing the descriptive evaluation increases knowledge in students, with 15 respondents i.e. $50 \%$ of the whole respondents.

Table 10. Maximum frequency of interviewed respondents to weakness factor

\begin{tabular}{llll}
\hline Gender & Response to weakness & Frequency & Percent \\
\hline Male & $\begin{array}{l}\text { Inadequacy of teachers skills for providing suitable } \\
\text { descriptive feedbacks to the students }\end{array}$ & 15 & $50 \%$ \\
Female & $\begin{array}{l}\text { Inadequacy of teachers skills for providing suitable } \\
\text { descriptive feedbacks to the students }\end{array}$ & 10 & $33 \%$ \\
\hline
\end{tabular}

The results of Table 10 show that the highest frequency distribution in male responses to the component of weakness is that inadequate ability of the teachers in giving proper descriptive feedbacks to the students is one of the weaknesses of this plan, with 15 respondents i.e. $50 \%$ of the whole respondents. 
The highest frequency distribution in female responses to the component of weakness is that inadequate ability of the teachers in giving proper descriptive feedbacks to the students is one of the weaknesses of this plan, with 10 respondents i.e. $33 \%$ of the whole respondents.

Table 11. Frequency and means of interviewed respondents to the factors of descriptive assessment

\begin{tabular}{lll}
\hline Factor & Frequency & $\mathrm{X}$ \\
\hline Strength & 327 & 16.35 \\
Weakness & 269 & 15.82 \\
Total & & \\
\hline
\end{tabular}

In Table 11, the frequency distribution and mean responses of the respondents to two components are examined. The results reveal that the mean response to the first component (strength) is higher than the other component. The findings indicate that gender, academic ranking and major does not influence the responses $(p>0.05)$. However, the respondents' opinions about challenges of interdisciplinary studies were different based on the type of activity that the company involved in $(\mathrm{F}=4.842, \mathrm{p}=0.011<0.05)$.

\section{Discussion and Conclusion}

Overall findings regarding consensus over the strengths of the descriptive evaluation in elementary schools showed that the teachers, principals, and experts have consensus over the strengths mentioned in the instrument, which indicates the strengths of the plan are acceptable for them. The strengths included increasing knowledge, increasing an interest in learning and increase in self-confidence in students. Therefore, according to teachers, principals and experts, performing descriptive evaluation will increase knowledge, self-confidence and interest in learning in students. Executives consider the most important strengths of the descriptive evaluation to be increasing knowledge in students and the least important one to be increasing interest and commitment to educational activities, which shows all parts of the components of strength are acceptable for executives. The findings are in line with those of Ebrahimi (2008) which showed that performing descriptive evaluation leads to the elimination of the culture which emphasizes A marks, an improved quality of learning-teaching process, increase in psychological health, decrease in stress and anxiety, increase in self-confidence, decrease in improper competitions, boosting the sense of responsibility and cooperation and enjoying studying. Regarding the examination of strengths of descriptive evaluation, the results are consistent with those of NikNezhad (2007), RazmAra (2006), KhoshKholgh and Sharifi (2006), MortezaeeNezhad (2005), Moosavi (2005), Karimi (2005), Mohammadi (2005), AbuMohammadi and Khanghaei (2004), Hassani and Ahmadi (2004), Beri (2004), Hebdige (2003), Wadel (2004), Arthur (2004), and Camp \& Teprov (1998) who showed that performing descriptive evaluation will lead to a decreased anxiety and increased psychological health in students as a result of the elimination of the culture which emphasizes on A mark, and that giving timely feedbacks will help the students learn better.

Regarding the findings about weaknesses, the consensus of the teachers over weaknesses of the plan were higher than average. Regarding the second question that examined the degree of consensus among teachers over the weaknesses of the plan, the results showed that the mean of the examined component was higher than average (3), which shows that teachers agree on the weaknesses of the plan. The components of weakness with the highest mean values included inadequate readiness of the performers to accept the descriptive evaluation ( $\bar{X}=4.57)$, inadequate resources allocated by the officials $(X=4.41)$, inadequate skill of the teacher in using defined tools for performing the descriptive evaluation $(\bar{X}=4.20)$, and inadequate sill of the principal in considering and monitoring the performance of the descriptive evaluation $(\bar{X}=4.20)$. Therefore, based on the opinions of the teachers, principals and experts, the weakness of the plan which has to be addressed include inadequate readiness of performers to accept the descriptive plan, although none of the weaknesses should be ignored. A comparison of mean scores for responses with the hypothesized mean (3) showed that these weaknesses are higher than average. These findings are consistent with those of Ebrahimi (2008) which indicated the weakness of the plan in changing, spreading and internalizing process, and with those of Manthegi (2008) which suggested involving teachers in the planning process and giving them independence in order to avoid potential resistance. In addition, the findings are consistent with those of Fulan and Pamfrite (1970) which showed training programs can help better perform the new plans. 
The results based on the gender of the teachers indicated that regarding the two components there was not a significant difference among men and women, i.e. both male and female teachers answered the same. The findings regarding position showed that there was a significant difference among the mean scores for the two components. This suggests that principals, teachers, and experts did not answer the questions the same. The results based on the number of working years showed that the mean scores for the strengths and weaknesses, there was not a significant difference among responses based on the number of working years. The results based on the academic degree showed that the mean scores for the two components were not significantly different, so there was not a difference between the strengths and weaknesses in the respondents' points of view based on their academic degrees.

\section{Practical Implications}

Given the fact that the most powerful strength of descriptive evaluation is increasing knowledge, interest in learning, and self-confidence in students, it is suggested that:

1) The training courses held for performing teachers should be of high quality and the teachers should be trained technically.

2) The components of the curriculum including the content of the books and teaching methods should be in line with the objectives of the plan and if necessary, they should be adapted.

3) It is essential that the educational sector have a better cooperation with the higher education sector using researches regarding the descriptive evaluation.

4) In order to perform any new plan, the facilities should be provided based on the results and objectives specified. Therefore, it is essential that the officials work hard to develop facilities in order for the plan to continue.

Since one of the most significant weaknesses of this plan is inadequate readiness of the performers to accept the plan, inadequate skill if the teacher in using the tools defined and heavy content of the score sheets of the plan, it is suggested that:

- In order to address this issue, the objectives, features and the importance of the plan should be clarified by providing proper training.

- Holding workshops for performers and sharing the experiences of other teachers in basic attitudes toward evaluation of learned things and practical skills in developing performance tests and making samples and checklists needed for descriptive evaluation.

- Developing a comprehensive guidebook and sending it to the teachers.

- Holding training classes for teachers and principals to inform them the changes, this plan might hold in the long run.

- Downsizing the classes, for example 15 students in each class, so that the teacher is able to interact with the students.

\section{References}

AbuMoahammadi, M., \& Khanghaee, B. M. (2004). A study of the viewpoints of elementary school teachers regarding descriptive evaluation in Yazd. The educational research council of the bureau of education in Yazd (unpublished dissertation).

Arther, L. A. (2004). An exploration of the impact of prior achievement. Task complexity, cultural knowledge, and performance feedback on mathematics self-efficacy and self- assessment of American Preadolescent students. Doctoral Dissertation, Howard University.

Berry, R. (2004). Teachers perception of their roles and their students roles in the formative assessment process. Australian Association for research in Education (AARE2004) Doing the public Good, Melbourne, Austealia. Retrieved from http://www. Aare. Edu. Au/04 pap/ber04978-pdf (August 21, 1996)

Bradby, H., Varyani, M., Oglethorpe, R., Raine, W., White, I., \& Helen, M. (2007). British Asian families and the use of child and adolescent mental health services: a qualitative study of a hard to reach group. Social Science \& Medicine, 65(12), 2413-2424. http://dx.doi.org/10.1016/j.socscimed.2007.07.025

EbrahimiDinani, A. (2007). A study of the strengths and weaknesses of the process of change in the qualitative-descriptive evaluation plan in elementary schools in Isfahan. MA thesis, Isfahan University (unpublished dissertation). 
Farstad, H. (2004). Competencies for life: some Implication for Education, National Institute technology, Oslo, Norway, Background paper to workshop, UNESCO, 47, the International Conference on Education, Geneva.

Foster, E. M. (2007). Can system integration improve mental health outcomes for children? Children and Youth Services Review, 29(10), 1301-1319. http://dx.doi.org/10.1016/j.childyouth.2007.05.004

Fullan, M., \& Promfret, A. (1977). Research on curriculum and instruction implementation, Review of Educational Research, 47(2), 355-397. http://dx.doi.org/10.3102/00346543047002335

Gest, S. D., Weish, J., \& Domitrovich, C. (2005). Behavioral predictors of changes in social relatedness and liking school in elementary school. Journal of school psychology. 43(4), 281-301. http://dx.doi.org/10.1016/j.jsp.2005.06.002

Ghazi, G. (2003). The relationship between form of instruction, achievement and perceptions of classroom climate. Educational research, 45(1), 83-93. http://dx.doi.org/10.1080/0013188032000086145

Habibi, F. (2008). A study of the challenges of using descriptive evaluation. Selected papers of Khoram Abad seminar, May, 2008, bureau of education, Lorestan, KhorramAbad: Shapoorkhast.

Hassani, M., \& Ahmadi, H. (2005). Descriptive evaluation: a new model in educational evaluation. Tehran: the organization of educational research and planning. Ministry of Education.

Hassani, M. (2006). A model for spreading innovation in the Iranian educational system. The educational innovations periodical, 15(5).151-177. http://www.noormags.com/view/fa/articlepage/110135

Hassani, M. (2008). A guidebook for performing qualitative-descriptive evaluation in classrooms. Tehran: Abed Publications.

Hebdige. R. (2003). Teacher Portfolio assessment. ERIC:ED385608.

Kanter, R. M., B. Stein, \& T. D. Jick. (1992). The Challenge of Organizational Change: How Companies Experience It and Leaders Guide It. New York: Free Press.

Karimi, A. (2005). The impacts of the new descriptive evaluation method on behavioral disorders in Shiraz elementary school students. Research report, Fars education organization (unpublished dissertation).

Kemp, J., \& Toperoff. D. (1998). Guidelines fore portfolio assessment in teaching English. Ministry of Education.

Khoshkholgh, I., \& Pasha Sharifi, H. (2006). An evaluation of the tentative performance of descriptive evaluation in some elementary schools in the country. Education periodical, 16(5). 159-173. http://www.noormags.com/view/fa/articlepage/364436

Loukas, A., Murphy, J. (2007). Middle school student perceptions of school climate. Examining protective function on subsequent adjustment problems. Journal of school psychology, 45(3), 293-309. http://dx.doi.org/10.1016/j.jsp.2006.10.001

Lubbers, M. (2006). The impact of peer relations on academic progress in junior high. Journal of school psychology, 44(6), 491-512. http://dx.doi.org/10.1016/j.jsp.2006.07.005

Manteghi, M. (2006). A study of the challenges of educational innovations. Tehran: The first conference of educational innovations, 24-38.

MehrMohammadi, M. (2002). Curriculum, attitudes, viewpoints and perspectives, Mashhad: Astan Ghods Razavi Publications.

MoghniZadeh, M. H. (2004). Necessity of measuring emotional intelligence and the implications of self-retrieved educational improvement. Retrieved from www.parsei.com/education

Mohammadi, F. (2005). A study of the impacts of descriptive evaluation on the self-esteem of 3rd grader elementary students in Tehran. MA thesis. AL Zahra University (unpublished dissertation).

MortezaeeNezhad, E. (2005). A study of the attitudes of teachers and parents on using descriptive evaluation in 1st and 2nd grades of elementary schools in Tehran in 2004-5 academic year, M.A thesis. Islamic Azad University of ShahreRei (unpublished dissertation).

Mussavi, S. Z. (2005). An opinion poll from performers of descriptive evaluation based on the objectives of the plan in 2004-2005 academic years. Research report. Qom bureau of education (unpublished dissertation).

Nevo, D. (1995). School-Based evaluation: A dialogue school improvement. New York. Jossey-Bass. 
Saeed, M., Gondel. M. B., \& Bushra. (2005). Assessment achievement of primary grader students and factors affecting achievement in Pakistan. The International Journal of Education Management, 19, 486-490. http://dx.doi.org/10.1108/09513540510617436

Sammons, D. R., \& Renynolds, S. (1997). School effectiveness and school improvement. Retrieved from http/www.aar.edu.au/confo.htm.

Seif, A. A. (2003). The concept of evaluation and its influence on the teacher's methodology and learning of students. Tehran: The first conference of educational evaluation, The Bureau of Educational Evaluation.

Sharifi, Hassan pasha. (2004). The evaluation of performance in the process of teaching - learning. Papers of the national conference of reforms in education, 323-341, Tehran: Educational research.

Stiggins, R. (2004). New Assessment Beliefs for a New School Mission. Phi Delta Kappan, 86(1), 22-27. Retrieved from https://docushare.prsd.ab.ca/docushare/dsweb/Get/Version-563/Stiggins\%20Paper\%20\%282\%29.pdf

Tawil, S. (2002). Curriculum change and social inclusion. Final report. the regional seminor held in Vilnius, Lithuania. December 2001, UNESCO.

Teresa, W. L. (2004). Formative assessment in general studies classrooms. Hong Kong Teachers Center Journal, 3, 141-154. Retrieved from http://repository.ied.edu.hk/dspace/handle/2260.2/7242

UNESCO, (2000). Globalization and Living together; the challenge for Educational Content in Asia, Final Report of sub- regionl Course on Curriculum development, New Delhi, India, March, 1999.

Van Evera, W. C. (2004). Achievement and motivation in the middle school science classroom: The effects of formative assessment feedback. Doctoral Dissertation, George Maason University.

Waddell, C. A. (2004). The effect of negotiated written feedback within formative assessment on fourth-grade students motivation and goal orientations. Doctoral Dissertation, University of Missouri - Saint Louis.

West, R., \& Crighton, J. (1999). Examination reform in central and Eastern Europe: Issues and trends, Assessment in Education, Principles, Policy \& Practice, 6(2), 271-289. http://dx.doi.org/10.1080/09695949992919 